\title{
Pelatihan Perawatan dan Service Kelistrikan Sepeda Motor Bagi pemuda Panti Sosial Asuhan Anak Binaan Remaja (PSAABR) Budi Utama Lubuk Alung Kabupaten Padang Pariaman
}

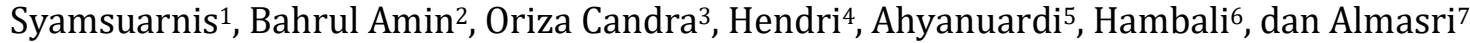 \\ 13456Jurusan Teknik Elektro, ${ }^{2} J u r u s a n$ Otomotif, 7Jurusan Elektronika, Fakultas Teknik, Universitas Negeri Padang \\ Jl. Prof. Dr. Hamka, Kota Padang, Indonesia \\ Corresponding author: orizacandra@ft.unp.ac.id
}

\begin{abstract}
Unemployment for people aged 15 years and over is a problem that never ends even though there has been a decline every year, but the decline is not significant when compared to the jobs that the workforce is engaged in. Indonesia, based on BPS data, in 2010 the open unemployment rate was $7.41 \%$, while in 2012 it was $6.32 \%$ of the total workforce over 15 years of age. The magnitude of the open unemployment rate has very fragile and broad social implications for people's lives, because they do not work and have no income. The higher the open unemployment rate, the higher the level of social vulnerability, it can even lead to higher crime rates. On the other hand, if the open unemployment rate can be suppressed and reduced, then social vulnerability will decrease and even increase high social awareness as a result of an increasingly equitable level of prosperity. The implementation of training on motorbike electrical maintenance and service was carried out for the youth of the Budi Utama Lubuk Alung Youth Assistance Social Institution (PSAABR), Padang Pariaman Regency by providing material in the form of basic knowledge and carrying out practices. The training was carried out in several sessions over 3 days with 15 participants. Exams are carried out at the beginning of the training and at the end of the training. The results obtained after the training are increasing the knowledge of drop-out youths about maintenance techniques and electrical service on motorbikes, the skills have increased as seen from the post test.
\end{abstract}

Keywords - Training, Youth social homes, Motorbikes.

\begin{abstract}
Abstrak- Pengangguran bagi penduduk usia 15 tahun ke atas adalah pertarungan yang tidak pernah berakhir meskipun semakin tahun masih ada penurunan namun penurunan tersebut sangat signifikan apabila dibandingkan menggunakan lapangan pekerjaan yang digeluti oleh angkatan kerja tersebut. Indonesia, dari data BPS, dalam tahun 2010 taraf pengangguran terbuka sebanyak 7,41\% sedangkan dalam tahun 2012 tercatat sebanyak 6,32\% dari total angkatan kerja usia pada atas 15 tahun. Besarnya taraf pengangguran terbuka memiliki akibat sosial yg sangat rawan dan luas terhadap kehidupan masyarakat, lantaran mereka belum bekerja dan belum memiliki pendapatan. Semakin tinggi taraf pengangguran terbuka meningkat taraf kerawanan sosial, bahkan bisa mengakibatkan taraf kriminalitas sebagai semakin tinggi. Sebaliknya, apabila taraf pengangguran terbuka bisa ditekan dan diperkecil, maka kerawanan sosial akan berkurang dan bahkan meningkatkan pencerahan sosial yang tinggi menjadi dampak berdasarkan taraf kemakmuran yang semakin merata. Pelaksanaaan pelatihan perawatan dan service kelistrikan sepeda motor dilakukan bagi pemuda Panti Sosial Asuhan Anak Binaan Remaja (PSAABR) Budi Utama Lubuk Alung Kabupaten Padang Pariaman dengan cara pemberian materi berupa pengetahuan dasar-dasar dan melaksanakan praktik. Pelaksanaan pelatihan dilakukan dalam beberapa sesi selama $\mathbf{3}$ hari dengan jumlah peserta 15 orang. Ujian dilakukan dilakukan diawal pelaksanaan pelatihan dan diakhir pelatihan. Hasil yang di peroleh setelah pelatihan adalah menambah wawasan pemuda putus sekolah mengenai teknik perawatan dan service kelistrikan sepeda motor, keahlian meningkat di lihat dari post test.
\end{abstract}

Kata kunci- Pelatihan, Pemuda panti sosial, Sepeda Motor.

\section{Pendahuluan}

Analisis situasi merupakan bagian penting dari isi proposal pengabdian kepada masyarakat yang menguraikan tentang gambaran secara kuantitatif potret, profil dan kondisi khalayak sasaran yang akan dilibatkan dalam kegiatan penerapan ilmu pengetahuan, teknologi dan seni (IPTEKS). Gambaran lokasi dan kasus yang terjadi dari segi sosial, budaya, mutu kehidupan masyarakat yang didukung dengan fakta dan data yang ada, serta permasalhan khusus yang dihadapi oleh mitra sesuai dengan buku panduan penelitian dan pengabdian kepada masyarakat. Panti Asuhan Budi Utama telah berdiri sejak tahun 1946 di Pekanbaru, Riau. Tahun 1950 pindah ke 
Lubuk Alung, Sumatera Barat. Tahun 1975, di lokasi itu juga didirikan Panti Karya Taruna (PKT). Kedua panti tersebut digabung pada tahun 1979 dan bernama Panti Sosial Bina Remaja Budi Utama. Tahun 2001 diganti nama menjadi PSAABR dan mejadi UPTD Dinas Sosial Provinsi Sumatera Barat berdasarkan Perda Provinsi Sumatera Barat nomor 1 tahun 2003. PSAABR mempunyai tugas pokok memberikan pelayanan kesejahteraan sosial bagi anak yatim, piatu , yatim piatu, terlantar, anak terlantar, putus sekolah dan anak keluarga miskin [1].

Panti Sosial Asuhan Anak Binaan Remaja (PSAABR) Budi Utama terletak di Lubuk Alung Kabupaten Padang Pariaman, terdiri dari beberapa jurusan diantaranya Jurusan Otomotif, Listrik, Elektronika, Pemakaian Listrik, dan lainnya. PSAABR menampung anak-anak dan remaja dari keluarga kurang mampu dan putus sekolah, juga menampung anak-anak binaan yang tersandung masalah hukum sejak tahun 2015 dan berasal dari seluruh Sumatera Barat. Terhadap anak-anak binaan hukum (ABH), diberikan pelatihan keterampilan dan pembinaan seperti anak-anak dan remaja yang lain juga ditambah dengan pembinaan mental yang lebih khusus. Jumlah anak binaan di PSAABR mencapai 80 anak yang terbagi ke beberapa jurusan dan untuk jurusan otomotif sebanyak 15 orang [2].

Berdasarkan hasil survey dan wawancara tim pelaksana dengan Pengelola Panti Sosial Asuhan Anak Binaan Remaja (PSAABR) Budi Utama di Lubuk Alung Kabupaten Padang Pariaman, bahwa pemuda-pemuda yang ada dipanti tersebut berasal dari utusan karang taruna di Sumatera Barta. Peserta pelatihan yang ada dipanti PSAABR setiap enam bulan terjadi pergantian peserta dan setelah enam bulan para peserta diberikan magang di perusahaanperusahaan yang ada di Sumatera Barat. Kegiatan yang akan dilakukan ini diikuti 15 peserta untuk setiap kompetensi Pemuda-pemuda yang berada di PSAABR merupakan pengangguran dan ada yang bekerja membawa ojek. Mereka sangat membutuhkan pembinaan dan pengembangan keterampilan hidup terutama yang putus sekolah dan tidak dapat melanjutkan kejenjang yang lebih tinggi. Keterampilan yang dibutuhkan adalah pengetahuan dan keterampilan yang dapat menjadikan mereka berjiwa mandiri dan wirausaha sehingga bisa meningkatkan taraf perekonomian [3].

Pelaksanaan keterampilan diperlukan instruktur untuk mentransfer keterampilan sehingga anak binaan panti memiliki kompetensi yang memadai untuk dapat berjiwa mandiri. Kendala saat ini adalah tidak adanya instruktur yang sesuai kompetensi yang diharapkan. Terkadang instruktur yang ada memberikan keterampilan berlainan dengan kompetensi yang dimilikinya. Kemudian belum adanya pelatihan dan peralatan yang berkaitan dengan panel surya dan selama ini setiap tahun sudah terlaksana kegiatan pengabdian di Jurusan Teknik Elektro dan Elektronika. Pengelola PSAABR berharap juga dilaksanakan kegiatan ini untuk jurusan Otomotif dan Mesin.
Berdasarkan analisis situasi terhadap kondisi penggunaan sepeda motor yang terus meningkat baik di perkotaan maupun di pedesaan dan kondisi yang ada di Panti Sosial Asuhan Anak Binaan Remaja (PSAABR) serta masalah yang telah diungkapkan di atas, tim pelaksana dan Pengelola Panti Sosial Asuhan Anak Binaan Remaja (PSAABR) Budi Utama di Lubuk Alung Kabupaten Padang Pariaman sepakat untuk memberikan pelatihan peningkatan keterampilan. Dalam hal ini kegiatan yang akan dilakukan adalah Pelatihan peningkatan keterampilan bidang dasar-dasar perawatan kelistrikan dan materi tambahan berupa materi mekanik sepeda motor. Selain sangat membantu mereka untuk memperoleh keterampilan juga membantu dalam mengembangkan kemandirian dan kewirausahaan dan akan menjauhkan mereka dari ketidakpastian masa depan [4].

Sasaran kegiatan ini pemuda-pemuda pilihan yang bearasal dari Karang Taruna dari seluruh Sumatera Barat yang diasramakan pada Panti Sosial Asuhan Anak Binaan Remaja (PSAABR) Budi Utama di Lubuk Alung Kabupaten Padang Pariaman Pemuda-pemuda adalah yang putus sekolah dan tidak dapat melanjutkan pendidikan yang lebih tinggi.

Pelaksanaan keterampilan diperlukan instruktur untuk mentransfer keterampilan sehingga anak binaan panti memiliki kompetensi yang memadai untuk dapat berjiwa mandiri. Permasalahan Mitra saat ini adalah tidak adanya instruktur yang sesuai kompetensi yang diharapkan. Terkadang instruktur yang ada memberikan keterampilan berlainan dengan kompetensi yang dimiliki oleh instruktur tersebut. Kemudian belum adanya pelatihan dan belum memiliki sarana yang memadai untuk menyelenggarakan paket keahlian Teknik Sepeda Motor [5].

Berdasarkan analisis situasi dan permasalahan yang diperoleh dari hasil survey maka diperlukan pelatihan untuk peningkatan kemampuan keterampilan bagi pemuda Panti Sosial Asuhan Anak Binaan Remaja (PSAABR) Budi Utama di Lubuk Alung Kabupaten Padang Pariaman dalam hal keterampilan bidang dasar-dasar perawatan kelistrikan dan materi tambahan tentang materi mekanik sepeda motor. Dengan diberikannya kompetensi tersebut diharapkan mereka memiliki kompetensi yang beragam sehingga dapat mempersiapkan kemandirian anak binaan panti dimasa yang akan datang.

\section{Metode}

Metode pelaksanaan yang dilakukan pada saat pelaksanaan kegiatan ini, baik bersifat teori maupun praktek adalah sebagai berikut:

\section{A. Sosialisasi Pelaksanaan Pengabdian}

Kegiatan ini dilakukan untuk memberitahukan dan mensosialisakian kepada PSAABR Lubuk Alung terkait program kegiatan pengabdian kepada masyarakat yang akan dilaksanakan dengan kelompok mitra. Output dari kegiatan berupa kesedian dari mitra untuk ikut 
berpartisipasi dalam kegiatan baik dari sisi waktu, tenaga, dan tempat pelaksanaan [6]. Output yang dihasilkan berupa terdaftarnya peserta pelatihan sebanyak 25 orang. Dengan ketentuan pemuda putus sekolah ataupun yang belum mendapatkan pekerjaan.

\section{B. Pengadaan Alat \& Bahan Pelatihan}

Kegiatan ini dilakukan untuk menginventarisir kebutuhan pelatihan perawatan dan materi tambahan tentang materi mekanik sepeda motor baik yang berupa peralatan maupun bahan yang digunakan. Untuk peralatan yang dipakai dikarenakan butuh investasi dengan dana yang besar untuk mengadakan sendiri maka dilakukan dengan cara sewa ataupun menggunakan fasilitas di kampus.

\section{Pemberian Materi}

Secara umum program pelatihan perawatan dan service kelistrikan sepeda motor ini bertujuan untuk menghasilkan peserta yang memiliki pengetahuan ketrampilan kerja, serta hak dan tanggung jawab dalam bidang perawatan dan service sepeda motor berikut sistem-sistemnya, kelistrikan sistem pemindah tenaga, rem, rangka dan suspensi, roda dan ban dalam rangka memelihara kondisi agar sesuai dengan standar spesifikasinya. Pemberian materi mengunakan metode ceramah, diskusi dan tanya jawab, dimana peserta diberi modul pembelajaran. Pemberian teori yang diberikan tidak hanya terkait dengan materi perawatan dan service sepeda motor.

\section{Praktek Perawatan dan Service Kelistrikan Sepeda Motor}

Pelaksanaan praktek perawatan dan service kelistrikan sepeda motor meliputi kegiatan sistem kelistrikan dan bongkar pasang engine yang sudah dijabarkan pada modul pelatihan. Dari kegiatan praktek ini, peserta diharapkan dapat melakukan perawatan dan service sepeda motor berikut sistem-sistemnya agar kondisi sepeda motor sesuai dengan standar spesifikasinya, mencakup kemampuan, antara lain; Mengidentifikasi, menggunakan, dan memelihara alat tangan (hand tools) dan alat ukur (measurement tools).

\section{E. Evaluasi Pelatihan}

Pelaksanaan kegiatan pengabdian masyarakat ini bertujuan untuk meningkatkan pengetahuan dan keterampilan peserta [7]. Peserta pelatihan merupakan pemuda-pemuda putus, sehingga dengan adamya kegiatan ini diharapkan dapat menjadi pemuda yang berswakarya dan dengan wirausahanya di bidang otomotif. Selama pelatihan berlangsung dilakukan tahapan evaluasi untuk mengukur seberapa jauh tingkat pemahaman dan pencapaian kompetensi teknik perawatan dan service kelistrikan sepeda motor yang telah ditetapkan.

\section{HASIL DAN PEMBAHASAN}

Kegiatan pelatihan dapat dilaksanakan pada September 2020 dengan melibatkan beberapa orang pemateri dan teknisi dari Jurusan Teknik Elektro dan Otomotif FT-UNP. Adapun aktifitas kegiatan pelatihan dapat dilihat pada gambar di bawah. Kegiatan pelatihan ini di mulai dari tahap persiapan antara lain, penyusunan rencana pengabdian, observasi, penyusunan proposal dan dilanjutkan tahap pelaksanaan yang di awali dengan pembuatan modul pelatihan, merumuskan dan membuat instrument tes dan observasi, kelengkapan fasilitas pelatihan, dan pelaksanaan pelatihan hingga tahap penyusunan laporan. Peserta yang menjadi khalayak sasaran kegiatan ini berjumlah 15 Peserta yaitu Pemuda putus sekolah binaan Panti Sosial Asuhan Anak Binaan Remaja (PSAABR) Budi Utama Lubuk Alung Kabupaten Padang Pariaman.

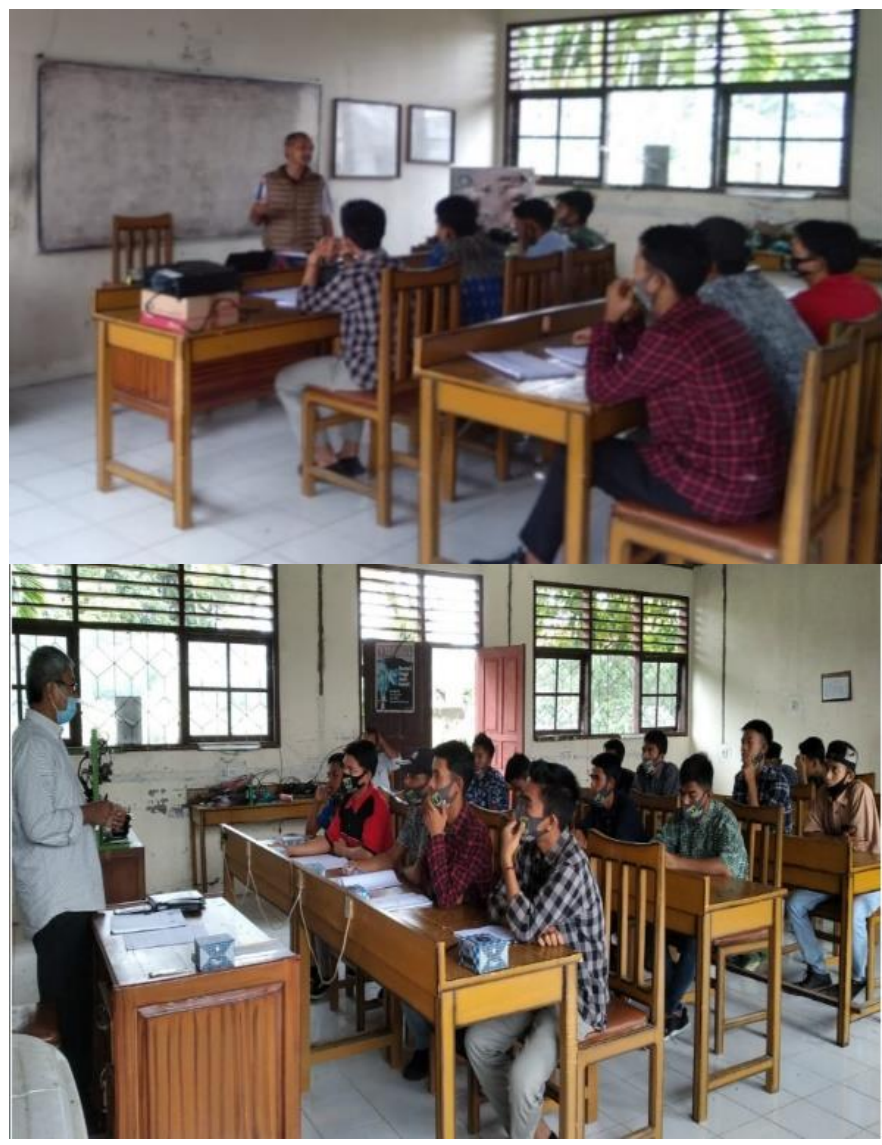

Gambar 1. Suasana Penyampaian Materi 

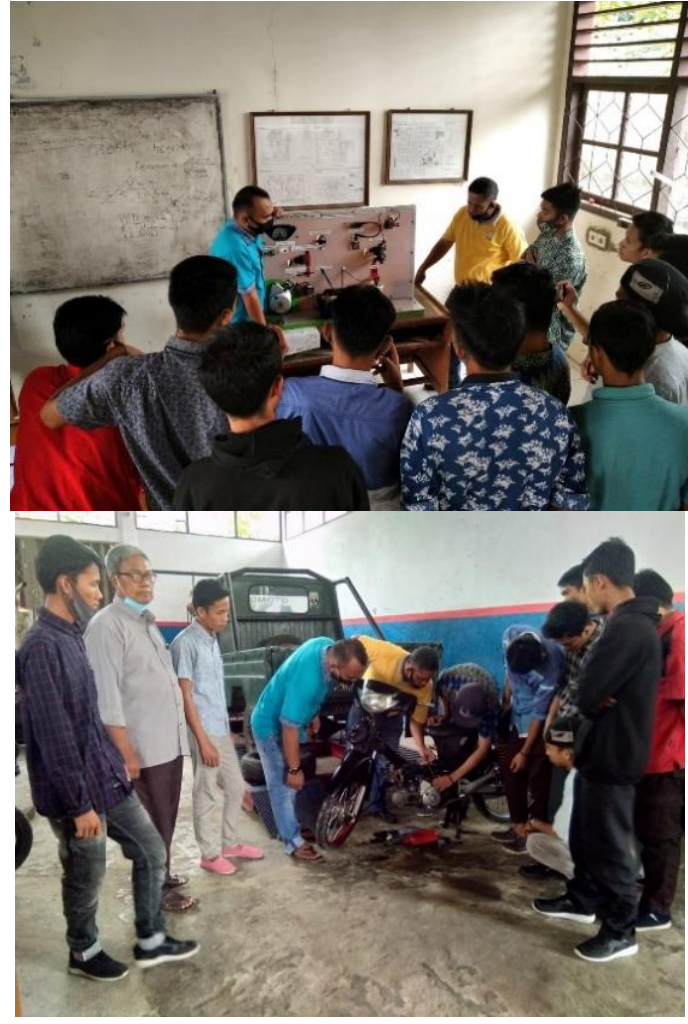

Gambar 2. Suasana Pelatihan

Tujuan akhir dari kegiatan pelatihan ini adalah memberikan pengetahuan dan pemahaman terhadap bagaimana cara melakukan Perawatan dan Service kelistrikan sepeda motor. Penilaian keberhasilan dari kegiatan ini dapat dilihat melalui kemajuan pengetahuan dan pemahaman serta keterampilan melalui perbandingan antara pre-test dan post-tes, dan juga keterampilan peserta dalam malakukan Perawatan dan Service kelistrikan sepeda motor yang dinilai melalui observasi.

\section{PENUTUP}

Berdasarkan hasil pelaksanaan kegiatan yang telah dilakukan, dapat ditarik kesimpulan, pengetahuan peserta mengenai perawatan dan service kelistrikan sepeda motor khususnya bagi pemuda Panti Sosial Asuhan Anak Binaan Remaja (PSAABR) Budi Utama di Lubuk Alung Kabupaten Padang Pariaman secara umum masih kurang memadai sebelum dilaksanakanannya pengabdian, Hal ini ditunjukkan dari hasil pre-test. Penyampaian pengetahuan tentang perawatan dan service kelistrikan sepeda motor kepada peserta pengabdian dapat berjalan lancar ini terlihat dari hasil post-test dan hasil kerja peserta, oleh karena itu di harapkan kepada peserta mampu meningkatkan pengetahuan dan taraf hidupnya setelah kegiatan ini terlaksana.

Metode pelatihan di buat secara sistematis, sehingga peserta mampu menerapkan di dunia kerja yang sesungguhnya. Berdasarkan pelaksanaan kegiatan ini telah berdampak positif terhadap peningkatan kemampuan peserta yang mengikuti kegiatan ini, baik dari segi proses maupun hasil. Dari segi proses, seluruh peserta antusias mengikuti kegiatan dari awal sampai akhir, sedangkan dari segi hasil peserta telah dapat melakukan perawatan dan service sepeda motor. Berdasarkan hasil evaluasi, diperoleh $100 \%$ atau seluruh peserta, nilainya mengalami peningkatan dibandingkan dengan nilai pada tes awal. Dengan kata lain dapat disebutkan bahwa telah terjadi peningkatan pengetahuan, pemahaman dan kemampuannya tentang perawatan dan service kelistrikan sepeda motor.

\section{REFERENSI}

O. Candra, N. Faradina, S. Islami, D. T. P. Yanto, and C. Dewi, "Peningkatan Kompetensi Bidang Instalasi Listrik Domestik bagi Pemuda Panti Sosial Asuhan Anak Binaan Remaja ( PSAABR ) Budi Utama Lubuk Alung Kabupaten Padang Pariaman," JTEV (Jurnal Tek. Elektro dan Vokasional), vol. 5, no. 2, pp. 22-27, 2019.

Elfizon, O. Candra, Syamsuarnis, and M. Muskhir, "Peningkatan Life Skill Reparasi Peralatan Listrik Rumah Tangga Bagi Pemuda Psaabr Budi Utama Lubuk Alung Kab. Padang Pariaman," J. Tek. Elektro dan Vokasional, vol. 5, no. 1, 2019.

A. Basri, "UPTD Panti Sosial Asuhan Anak Bina Remaja (PSAABR) 'Budi Utama' Jl. M Yamin Sh Lubuk Alung," 2013. https://sumbarprov.go.id/home/news/700-uptd-pantisosial-asuhan-anak-bina-remaja-psaabr-budi-utama-jlm-yamin-sh-lubuk-alung.html.

O. Candra, F. Eliza, S. Islami, and Y. Alisman, "Pengembangan Multimedia Interaktif Mata Diklat memperbaiki Motor Listrik guna Peningkatan Hasil Belajar," Perspekt. Pendidik. dan Kegur., vol. X, no. 2, pp. 7-15, 2019.

D. W. Pratama, D. Widjanarko, and Wahyudi, "Pengembangan Jobsheet Praktikum untuk Meningkatkan Kompetensi Dasar Perbaikan Sistem Continously Variable Transmission (CVT) Sepeda Motor," Automot. Sci. Educ. J., vol. 3, no. 1, pp. 1-5, 2014.

[6] S. Syamsuarnis and O. Candra, "Pembangkit Listrik Tenaga Angin sebagai Energi Listrik Alternatif bagi Masyarakat Nelayan Muaro Ganting Kelurahan Parupuk Kecamatan Koto Tangah," JTEV (Jurnal Tek. Elektro dan Vokasional), vol. 6, no. 2, p. 44, 2020, doi: 10.24036/jtev.v6i2.108487.

[7] Hambali, E. Astrid, Hendri, and S. Islami, "Penyuluhan dan Pelatihan Instalasi Listrik Rumah Tangga bagi Masyarakat di Nagari Pauh Duo Nan Batigo Kecamatan Pauh Duo Kabupaten Solok Selatan," JTEV (Jurnal Tek. Elektro dan Vokasional), vol. 6, no. 1, pp. 98-102, 2020. 